\title{
PRÁTICAS DOCENTES E RELAÇÕES RACIAIS EM UMA CRECHE DO MUNICÍPIO DO RIO DE JANEIRO
}

TEACHING PRACTICES AND RACE RELATIONS IN A DAY CARE CENTER IN THE CITY OF RIO DE JANEIRO

Aline de Oliveira Braga Maria Alice Rezende Gonçalves

\section{Como citar este artigo:}

BRAGA, Aline de Oliveira; GONÇALVES, Maria Alice Rezende. Práticas docentes e relações raciais em uma creche do município do Rio de Janeiro. Cadernos do Lepaarq, v. XVII, n.34, p. 26-43, Jul-Dez. 2020. 


\title{
Práticas docentes e relações raciais em uma creche do município do Rio de Janeiro
}

\author{
Aline de Oliveira Braga ${ }^{\mathrm{a}}$ \\ Maria Alice Rezende Gonçalves ${ }^{\mathrm{b}}$
}

\section{Resumo:}

Este artigo tem como objetivo descrever as relações raciais entre os profissionais da educação infantil, os bebês negros e seus responsáveis em uma creche do município do Rio de Janeiro. Os pressupostos teóricos são: a noção de racismo estrutural (FANON, 1968, 2008), de técnicas corporais (MAUSS, 2003, 2011), de identidade negra e de cabelo crespo (HOOKS, 2005) e nas contribuições de pesquisadores nacionais, como Gomes (2008), Figueiredo (2008) e Malachias (2007), entre outros. Os discursos construtores de subjetividades que reforçam a subalternidade da criança negra são produzidos na sociedade e reproduzidos no cotidiano escolar da educação infantil por meio das falas e ações dos profissionais da educação, como também nas dos responsáveis pelos bebês desvalorizando as características fenotípicas negras. Assim, apontamos para a necessidade de uma formação docente fundada nos pressupostos de uma educação antirracista.

\section{Palavras-chave:}

Educação infantil. Relações étnico-raciais. Práticas docentes. Creche.

\begin{abstract}
:
This article aims to describe the racial relations between the professionals of the nursery education, the black babies and their caregivers in a day care center in the city of Rio de Janeiro. The theoretical assumptions are: the notion of structural racism (FANON, 1968, 2008), body techniques (MAUSS, 2003, 2011), black identity and curly hair (HOOKS, 2005) as well as theories from other national researchers such as: Gomes (2008), Figueiredo (2008) and Malachias (2007) among others. The constructive of subjectivity speeches that reinforce the subalternity of the black child are produced in society and reproduced in the school daily life of children's education through the speeches and actions of education professionals, as well as those responsible for infants devaluing black phenotypic characteristics. Thus, we point to the need for teacher education based on the assumptions of an antiracist education.
\end{abstract}

\section{Keywords:}

Child education. Ethnic-racial relations. Teaching practices. Day care center.

\footnotetext{
${ }^{a}$ Secretaria Municipal de Educação do Rio de Janeiro. E-mail: alineoliveira-18@hotmail.com

${ }^{\text {b}}$ Universidade do Estado do Rio de Janeiro. E-mail: marialicerezende@gmail.com
} 
Quem disse que cabelo não gosta de pente

Cabelo quando cresce é tempo

Cabelo embaraçado é vento

Cabelo vem lá de dentro

Cabelo é como pensamento.

(Cabelo, Jorge Bem e Arnaldo Antunes)

O debate em torno do cabelo crespo tendo sido um tema recorrente nas discussões sobre a construção da identidade positiva negra. No entanto, ainda persistem tanto na sociedade práticas racistas que reforçam a inferioridade do negro a partir de suas características, e o cabelo é uma delas. Este artigo tem como objetivo descrever as relações raciais entre os profissionais da educação infantil, os bebês negros e seus responsáveis em uma creche municipal. Tomamos com pressupostos teóricos a noção de racismo estrutural produtor de desigualdades que separam brancos e negros (FANON, 1968, 2008), a noção de técnicas corporais transmitidas por meio da educação (MAUSS, 2003, 2011) e o debate sobre educação infantil, racismo e cabelo crespo presente na obra de vários pesquisadores nacionais e internacionais. Gomes (2008), bell hooks (2005), Figueiredo (2002), Silva Júnior (2002), Rosemberg (2012), Cavalleiro (2000), Miranda e Martins (2007), Oliveira e Abramowicz (2010), Guimarães (2011) e Malachias (2007) contribuem para a discussão sobre a importância da diversidade na educação infantil e a valorização da formação da identidade racial negra na primeira infância.

Vários autores discorrem sobre temáticas relacionadas à infância da criança negra no Brasil, e propõem meios de modificar questões que persistem no âmbito escolar, como o racismo e o preconceito manifestado em relação ao negro em seu processo de entrada na escola. Ao adentrarmos à questão racial no Brasil, deparamo-nos com as marcas de uma sociedade que privilegia o aspecto racial europeu como sinônimo de beleza. É nesse sentido que devemos atentar para a importância de se promover um ambiente onde as crianças e os bebês recebam uma educação que valorize a sua identidade, despertando sua sensibilidade para a diversidade que os cercam. A educação e o cuidado da criança negra que frequenta a creche devem ser estabelecidos mediante a preocupação com o desenvolvimento de práticas reflexivas sobre atos, ações, o movimento do corpo, o abraço e as palavras, pois a infância percebe, ouve e sente. Sendo assim, esses são os principais elementos de ligação entre os profissionais da educação e os bebês e devem ser pensados enquanto meios de se cuidar/educar para as relações étnico-raciais.

Entendemos por racismo o tratamento diferenciado entre raças na sociedade e no interior das instituições como a escolar. No cotidiano escolar, essas práticas se manifestam no tratamento, na preferência, no privilégio de um grupo em detrimento de outro de forma direta ou indireta, sem respaldo legal. Partimos do pressuposto de que a educação infantil de qualidade permite que a criança desenvolva habilidades sociais, emocionais e cognitivas que as ajudam a ter mais sucesso na vida escolar. Nesse sentido, as práticas racistas podem servir de barreiras que impediriam as crianças negras a obterem um bom desempenho no sistema de ensino. 


\section{ETNOGRAFANDO AS PRÁTICAS DE UMA CRECHE: DOCENTES, AUXILIARES, BEBÊS E SEUS RESPONSÁVEIS}

Esta etnografia, realizada de 2014 a 2015, nos ajuda a tornar visíveis as práticas racistas disfarçadas de "subjetividades" presentes nas práticas docentes. Adotamos como pressuposto que o racismo pode ser identificado nas formas de condução das políticas públicas, nas práticas pedagógicas que resultam na diferenciação de tratamento entre crianças brancas e negras e no discurso dos responsáveis pelas crianças brancas e negras. Esses procedimentos que circulam informalmente escola reforçam estereótipos que inferiorizam as crianças dotadas de fenótipo negro.

No ambiente da creche, são construídos os primeiros suportes para a criança e as experiências vividas nesta etapa da vida são fundamentais para o seu desenvolvimento enquanto sujeito de direitos, como apontou a Constituição Federal de 1988, ao se referir à primeira infância. A criança recebe, por meio das ações dos adultos, os seus primeiros referenciais de comportamento. Assim, nos reportamos para a importância de práticas que respeitem as diferenças entre as infâncias presentes na creche.

A pesquisa teve início em 2014 na creche Céu Azul, localizada no centro de uma grande favela na periferia do Rio de Janeiro. Os moradores, professores e demais profissionais costumam ter acesso ao local através de duas ruas e algumas vielas bem estreitas. A rua principal é cercada por casas e pequenos comércios que atendem as necessidades dos moradores. A cultura local é formada por uma grande parcela de nordestinos, donos de padarias e artesões que fabricam gaiolas.

O Berçário 1 (de 6 a 12 meses) e o Berçário 2 (12 a 24 meses) são os primeiros contatos da criança com a creche. No Berçário 1 elas recebem os estímulos para se desenvolverem através de músicas, histórias e brincadeiras. Nos berçários eles já começam a falar e a andar. Desse modo, as práticas pedagógicas são de acordo com essas fases.

A pesquisa teve continuidade em 2015 na sala do Berçário 2. Os bebês acompanhados passaram pela transição de mudança de sala, pois ficaram mais velhos, e em sua antiga sala ingressaram novos bebês. Assim, prosseguimos com entrevistas e observações com a nova professora e suas auxiliares.

$\mathrm{Na}$ creche, observamos as relações raciais estabelecidas pelos profissionais da educação infantil, professores e auxiliares, com os bebês no ambiente do berçário. Os docentes, regentes de turma tinham formação pedagógica em cursos de formação de professores de nível médio ou superior, com graduação em pedagogia. Aos auxiliares de creche foi exigido, no momento do ingresso no funcionalismo público, somente o ensino fundamental.

Durante o trabalho de campo também observamos e entrevistamos duas docentes e cinco auxiliares, a gestora da unidade e oito responsáveis pelos bebês. Apresentamos as observações das múltiplas vozes e olhares sobre os corpos e ações de 25 crianças ( 8 negras e 17 brancas) que frequentam o berçário. Os sujeitos da investigação foram oito bebês negros e suas interações com os adultos que direcionam as ações do cuidar e de educar na creche. O quadro a seguir é composto pelos nomes fictícios dados aos bebes e aos seus responsáveis. A cor dos pais foi autodeclarada. 


\begin{tabular}{|l|l|l|}
\hline \multicolumn{1}{|c|}{ Crianças } & \multicolumn{1}{c|}{ Idade } & Responsável entrevistado \\
\hline Rita & \multirow{2}{*}{2 anos } & Jucélia (mãe) \\
\cline { 1 - 1 } Paulo & & Marta (mãe) \\
\cline { 1 - 1 } Daniel & & Carminda (avó) e Sandra (mãe) \\
\cline { 1 - 1 } Dora & & Amanda (avó) \\
Áurea & & Ferdinanda (avó) e Anita (mãe) \\
\hline Ângelo & Bianca (mãe) \\
\hline Nilza & & Inês (mãe) \\
\hline Eliane & Eduarda (avó) e Benedita (mãe) \\
\hline
\end{tabular}

Quadro 1 - Bebês e responsáveis

\begin{tabular}{|l|l|l|l|l|l|}
\hline \multicolumn{1}{|c|}{ Nome } & \multicolumn{1}{|c|}{ Idade } & \multicolumn{1}{c|}{ Cor } & \multicolumn{1}{c|}{ Escolaridade } & \multicolumn{1}{c|}{$\begin{array}{c}\text { Tempo na } \\
\text { função }\end{array}$} & \multicolumn{1}{c|}{ Cargo na creche } \\
\hline Maria & 46 anos & Branca & Ensino normal & 2 anos & Professora \\
\hline Débora & 34 anos & Branca & Superior completo & 2 anos & Professora \\
\hline Karina & 36 anos & Parda & Ensino normal & 10 anos & Agente auxiliar de creche \\
\hline Angélica & 28 anos & Morena & Ensino médio & 7 anos & Agente auxiliar de creche \\
\hline Janete & 27 anos & Branca & $\begin{array}{l}\text { Superior em andamento } \\
\text { (Pedagogia) }\end{array}$ & 5 anos & Agente auxiliar de creche \\
\hline Carla & 45 anos & Branca & Ensino médio & 3 anos & Agente auxiliar de creche \\
\hline Ruth & 30 anos & Parda & Superior completo & 3 anos & Agente auxiliar de creche \\
\hline Rosa & 50 anos & Branca & Superior completo & 10 anos & Diretora \\
\hline
\end{tabular}

Quadro 2 - Perfil das educadoras, auxiliares e gestora da creche

A primeira mãe que aceitou ser entrevistada era sempre elogiada pela professora Maria, por ser uma responsável que estimula sua filha, fortalecendo a identidade negra, por meio de brinquedos que possuem alguma identidade racial com a criança, como bonecas negras. Todas as entrevistadas são moradoras da favela onde está localizada a creche municipal. O quadro a seguir apresenta o perfil das profissionais que trabalham na creche.

Nos berçários, a equipe pedagógica costuma falar frequentemente sobre os cabelos das crianças brancas e negras. As falas relacionadas aos cabelos crespos, principalmente nos momentos de cuidado são depreciativas, como: cabelo ruim, pixaim, difícil de cuidar, sugerindo que os cabelos devem ser manipulados por produtos químicos, que resultariam em alisamento ou relaxamento dos fios. Já os cabelos lisos ou ondulados são classificados pelas profissionais como cabelo bonito, melhor, etc.

A professora Maria atuou durante 5 anos como agente auxiliar de creche. Ela se tornou professora dos bebês do Berçário 1 há cerca de um ano. A educadora passou por inúmeras creches como agente, mora próximo ao local de trabalho. Como já mencionou em diversas ocasiões, é fruto de um casamento inter-racial em que a mãe é negra e o pai é branco. Apesar seus cabelos anelados, ela se considera uma mulher branca por ter a pele mais clara em relação à da sua mãe. A sua visão referente à raça embasa seus sentidos, percepções e ações, ela se vê no papel de uma 
mulher branca que lida no cotidiano escolar com alunos, pais e colegas de trabalho que são negros. Em conversas informais, a professora relatou que alisava os cabelos desde a década de 1970, já que, quando criança, sua mãe a fazia acreditar na importância de ter cabelos lisos. Durante a infância e a juventude, utilizava o pente quente, relaxamentos e, posteriormente, escova e prancha. Sua família sempre cultivou a ideia de que o negro precisava usar os cabelos lisos e de que seu cabelo sem os métodos de alisamento era ruim. O negro tem suas primeiras experiências com o cabelo crespo muito cedo. Durante a infância, ocorrem os primeiros momentos de intervenção. Segundo Gomes (2008, p. 184):

\begin{abstract}
As experiências do negro em relação ao cabelo começam muito cedo. Mas engana-se quem pensar que tal processo inicia-se com o uso de produtos químicos ou o alisamento do cabelo com pente ou ferro quente. As meninas negras, durante a infância, são submetidas a verdadeiros rituais de manipulação do cabelo, realizados pela mãe, pela tia, pela irmã mais velha ou pelo adulto mais próximo. As tranças são as primeiras técnicas utilizadas. Porém, nem sempre elas são eleitas pela então criança negra, hoje, uma mulher adulta, como o penteado preferido da infância.
\end{abstract}

Desse modo, para o negro os cuidados com o corpo são uma forma de romper com os apelidos e os estereótipos negativos. Assim, Maria acreditou por décadas que precisava seguir sua trajetória com os cabelos lisos, mas ao ingressar na creche, ela mencionou que conheceu uma professora que cultivava seus cabelos crespos como ato político. A partir disso, repensou a sua história e o sentido de alisar os cabelos. Atualmente, usa seus cabelos sem alisamento e realiza um ritual de cuidados, aprendidos através de blogs que incentivam o uso do cabelo crespo.

A mulher negra ainda convive com o sentimento de rejeição ao cabelo crespo, um problema que já nasce na infância, no âmbito familiar, pois surge nas conversas domésticas, nas falas de nossas mães, irmãs, avós que vivenciaram e ainda vivenciam a ideia de que bonito é o cabelo liso. Esses relatos também são apresentados por bell hooks ${ }^{1}$ (2005), que trata de histórias da lida com o cabelo, dos rituais com o pente quente, técnicas de manipulação do cabelo utilizadas em nome de uma aparência embranquecida e livre de apontamentos. Ainda podemos identificar a situação do passing, em que a adoção das características do branco significa prestígio social. Quando a mulher negra assume a identidade branca apagando todos os sinais de sua vinculação com os negros a pessoa passa a fingir que é branca. A decisão da professora Maria em assumir uma identidade negra, não parece se tratar de um caso de passing.

A segunda regente de turma, Débora, atua há três anos na creche. A professora da segunda fase conviveu muito pouco com os bebês e durante a sua breve presença, mostrou-se pouco aberta ao tratamento da questão racial em sala de aula, embora tenha ressaltado em algumas falas a importância de se respeitar as diferenças naquele espaço.

Karina, agente auxiliar de creche, terceirizada, mora na comunidade e trabalha há 10 anos como auxiliar nesse local. Ela sempre fala sobre as histórias da criação do local, funcionários antigos, pessoas que de alguma forma contribuíram para a funcionalidade do ambiente. A funcionária é

A autora utiliza seu nome, bell hooks, com letras minúsculas. 
negra, possui cabelos crespos cultivados com técnicas de relaxamento. No primeiro contato, Karina perguntou à pesquisadora se ela também fazia relaxamento capilar, ao que esta respondeu que seus cabelos eram sem "química" (referindo-me ao processo de alisamento) e que apenas cuidava com tratamentos caseiros. Karina gostava muito de dicas sobre beleza e, em especial, sobre cremes para tratamento. A auxiliar "relaxa" (técnica de alisamento) os cabelos há muitos anos e preza muito que eles estejam baixos, sem volume. Durante algumas situações, ela mostrou repetitivamente que carrega consigo as marcas do racismo - alisa os cabelos como forma de se proteger das falas racistas - que prevalece como estruturador de nossa sociedade. Sua fala relacionada ao cabelo em diferentes momentos tem a oposição entre bom x ruim. Conforme discorre Hooks (2005, p. 4):

Aos olhos de muita gente branca e outras não negras, o black parece palha de aço ou casco. As respostas aos estilos de penteados naturais usados por mulheres negras revelam comumente como o nosso cabelo é percebido na cultura branca: não só como feio, mas como atemorizante. Nós tendemos a interiorizar esse medo. 0 grau como nos sentimos cômodas com o nosso cabelo reflete os nossos sentimentos gerais sobre o nosso corpo.

Os modelos de beleza e de prestígio são inseridos no subjetivo das crianças que desejam se visualizar também como bonitas. Nessa perspectiva, a divulgação midiática é um mecanismo de disseminação do racismo e de visibilidade deste, pois é possível observar como o preconceito, a ausência de mobilidade social, a representação negativa, a hipersexualização da mulher negra, as falácias em torno do cabelo crespo ainda preponderam socialmente, forjando as relações raciais.

Carla, a segunda agente auxiliar, é funcionária da rede municipal, uma mulher branca, que já morou na comunidade. A agente é concursada há poucos anos e trabalhou como vendedora anteriormente. Ela é sempre muito alegre e gosta de realizar brincadeiras com os bebês; gosta também de penteá-los e ressalta nesses momentos o quanto acha bonito os cabelos cacheados. Durante as entrevistas, percebemos que parte das mães se sentia prestigiada por ser ouvida a respeito de suas opiniões sobre a educação das relações raciais na creche. As entrevistas aconteceram na sala de leitura da creche, onde os responsáveis e os profissionais da educação foram ouvidos individualmente e em dias diferentes. A gestora da instituição achou a pesquisa de suma importância, pois percebia que a maioria dos negros alisavam os cabelos sobre esta investigação, destacando a importância de tratar esse tema na educação infantil. Inês, mãe de uma menina negra, comentou sobre a importância da educação infantil para o desenvolvimento da criança: "A educação infantil é uma base para o futuro da criança, eu acho assim. Nós, pais, educamos em casa, mas na escola dá mais aquele traquejo pra criança se desenvolver, falar melhor, se associar com as outras crianças."

Consideramos que os pais ressaltem os aspectos positivos da educação infantil, esse olhar mostra como a educação recebida na creche é prezada como forma de desenvolvimento e interação, ou seja, a educação e o cuidado recebidos são vistos como porta de entrada para a aprendizagem. Além disso, a creche é também um espaço para a criança pequena desenvolver sua autonomia e liberdade, pois todo o seu espaço foi pensando para atender as necessidades da infância. Silva Júnior (2012, p. 84) propõe que as "atitudes extremas de racismo, na escola e em outros espaços, ainda não são denunciadas sistematicamente, nem pelas famílias ou alunos, nem por cidadãos que 
se responsabilizem por mover ações públicas contra a discriminação em sala."

Rosemberg $(2011,39)$ observa que "os estudos sociais sobre infância e pesquisas e estudos sobre educação infantil têm dado pouca atenção às relações raciais." Cavalleiro (2000) analisa a discriminação sofrida por crianças negras em sala de aula. A autora aponta como uma das características de uma educação antirracista o repúdio a qualquer atitude preconceito e discriminatório na sociedade e no espaço escolar e cuidado para que as relações interpessoais entre adultos e crianças, negras e brancas sejam respeitosas. A obra de Miranda e Martins (2007, p. 11) discorre sobre o conceito de maternagem e evidencia a sua importância na construção identitária dos bebês negros: "Os profissionais responsáveis pela educação infantil estão inseridos em um contexto social que não aprendeu a conviver com as diferenças étnicas. Dessa forma, não estão isentos de reproduzir, mesmo que inconscientemente, valores, crenças, atitudes preconceituosas." Oliveira e Abramowicz (2010) alertam para necessidade de se criar outro tipo de educação para produção de novas crianças e outras infâncias que abordem aspectos de nossa realidade social, cultural, econômica e, sobretudo, racial.

No contexto dessa reflexão, contemplamos na entrevista perguntas sobre a importância da cor da pele e dos cabelos crespos. A entrevistada Inês prossegue, alertando para as contradições existentes na experiência cotidiana, ou seja, o tratamento diferenciado quando se trata de religião e raça:

Acho que no mundo todo [é importante] porque há muita desigualdade. Às vezes você entra num lugar com um torso no cabelo que eu gosto de usar, as pessoas te olham diferente, aí já parte para o lado da religião, acham que aquele torso que você está usando é por causa da sua religião, e não é. É o look que a pessoa quer usar, é o jeito. Eu, por exemplo, não gosto de alisar o cabelo, gosto do meu cabelo assim do jeito que ele é, mas tem gente que vê essa diferença por causa da nossa cor.

Ao descrever os efeitos psíquicos produzidos pelo racismo no negro, Fanon (1968) observa que o colonialismo diluiu o racismo, oprimindo o outro e dizimando sua cultura, origem e religião. As relações raciais foram envolvidas em violência psíquica que forjou domínios capazes de debilitar o sentimento de pertencimento do sujeito. A cultura foi fragmentada e desvinculada de sua condição de cultura para se tornar exotismo. A cultura negra, as raízes históricas, culturais e religiosas do povo negro foram inferiorizadas pelo branco. Na construção do Brasil, o negro e seus elementos de pertencimento estiveram à margem da sociedade. As normas estéticas também se contrapõem à religião, pois como Inês ressaltou, ela sofre com os olhares que ligam o seu torso nos cabelos à religião afro-brasileira e à cor da pele. Como em nossa sociedade ainda há preconceitos relativos à religião, o cabelo enfeitado pelo torso é olhado como algo que ostenta os elementos da religião de matriz africana.

O cabelo crespo é o mais difícil de cuidar, ele é crespo, na realidade lá na raiz ele é fino, então se você usar qualquer tipo de creme ele vai ficar aquele cabelo revoltado. Por exemplo, o meu cabelo é durão mesmo, eu uso cremes pra dar uma textura melhor, é caro mas deixa com uma textura boa, minhas filhas todas elas têm o cabelo cacheadinho, mas eu procuro cuidar igual. (Inês, mãe). 
A experiência de ser negra e alisar os cabelos está presente nas reflexões de Hooks (2005) e ganha sentido dentro do contexto brasileiro, em que o embranquecimento é difundido nos espaços sociais. Carminda, 45 anos, é cozinheira e tem ensino médio incompleto. É por meio de sua renda que sustenta seus netos. Como ela afirma:

A educação infantil é importante, é bom. A educação a gente começa em casa e termina na escola. Porque se criança não for bem educada em casa, ela não vai ser bem educada na escola. E até agora minha neta tá se desenvolvendo muito bem. [...] A cor da pele não tem importância, não sou racista. Pra mim tanto faz branco, preto, azul, moreno, porque tenho uma neta morena e a outra loira. Lá em casa os cabelos são diferentes, são loiros, morenos, pretos, duros, lisos, cacheados. Aí não vejo diferença nisso. (Carminda, avó de Daniel).

Na perspectiva de Carminda, a educação infantil é um importante meio de aprendizado. Ela considera também que esse aprendizado age em conjunto com a família, ou seja, a criança leva para a creche a educação, os conhecimentos recebidos em casa, evidenciando como a instituição familiar e seus valores são partes vitais da construção identitária. Quanto ao preconceito racial, Anita, mãe de Áurea relata: "É sem preconceito, né? Eu não tenho preconceito à cor de pele nenhuma, pra mim é tudo a mesma coisa."

O corpo representa valores históricos, pois expressa o encontro cultural do negro com sua ancestralidade. A diversidade brasileira está presente na composição familiar da avó entrevistada (ou mãe-avó), que retrata, através de sua fala, o quadro racialmente diverso, fruto da mestiçagem, da população brasileira. A fala de Sandra, a seguir, reflete o que ainda ocorre no dia a dia do negro, no cotidiano escolar, nas mídias, nos discursos. A cor da pele motiva olhares, tratamentos diferenciados, invisibilidade, o que, em sua visão já está demarcado como algo difícil de tirar do mundo, pois "infelizmente é o mundo que a gente vive". A sua voz, ao ser ouvida, refletida, reafirma o quanto precisamos desconstruir as ideologias racistas:

\footnotetext{
Tem racismo no Brasil é muito. A gente ainda vê muito preconceito nas pessoas que é negra. A gente ainda vê muito racismo, infelizmente. Às vezes na rua o jeito dos outros tratar, às vezes também, tem o racismo pela pessoa ser de outro jeito. As pessoas de hoje em dia não é assim como a gente queria que fosse, mas infelizmente é o mundo que a gente vive e a gente tem que ir levando aos poucos. (Sandra, mãe de Daniel).
}

A correção do estigma que o negro carrega também vai ao encontro da superação da ideia de que todos são tratados com igualdade, independentemente de ser negro ou branco no Brasil. Nessa tarefa, devemos caminhar em busca de novos rumos em que a escola e a sociedade se tornem constituintes de um cenário que insufle a valorização da diversidade.

\section{INFÂNCIA, CORPO E EDUCAÇÃO}

Os elementos apresentados são parte do que se configura como fruto da etnografia feita na creche dentro do espaço do berçário, que tem como meta contribuir para a investigação da questão racial na educação infantil, a partir de observações que visam identificar nas práticas 
pedagógicas como são tratados os marcadores de identidade étnico-racial das crianças negras. 0 modelo metodológico etnográfico permitiu o relato das experiências iniciais dos bebês negros no âmbito da creche.

Nessa perspectiva, é por meio do corpo, do contato, dos gestos e ações que educamos, marcamos e imprimimos as sensações, amparos e questões. No corpo está presente a própria existência do sujeito. O corpo cuidado, afagado, educado é de natureza biológica e cultural, pois nele se encontra a vida e a cultura. Marcel Mauss (2003, p. 405) afirma que:

A noção de educação podia sobrepor-se à noção de imitação. Pois, há crianças, em particular que têm faculdades muito grandes de imitação, outras que as têm bem fracas, mas todas passam pela mesma educação, de sorte o que podemos compreender a sequência dos encadeamentos. O que se passa é uma imitação prestigiosa. A criança como o adulto imita atos que obtiveram êxito e que ela viu serem bem-sucedidos em pessoas em quem confia e que têm autoridade sobre ela. O ato impõe-se de fora, do alto, ainda que seja um ato exclusivamente biológico e concernente ao corpo. O indivíduo toma emprestado a série de movimentos de que ele se compõe ao ato executado à sua frente ou com ele pelos outros.

Os comportamentos são aprendidos socialmente e formam hábitos (MAUSS, 2003) que compreendem as educações, as modas, os próprios comportamentos. As técnicas corporais são transmitidas por meio da educação. A sociedade desenvolveu uma pedagogia dos corpos, efetuada através do processo de sua moldagem e controle. Como indica Mauss (2003), há um conjunto de atitudes permitidas ou não, naturais ou não. Assim, somos conduzidos a nos comportar segundo os valores sociais que nos foram introjetados através das técnicas corporais.

\section{O COTIDIANO ESCOLAR: AS EXPERIÊNCIAS DA CRIANÇA NEGRA NA CRECHE}

O contexto de que falamos está expresso em diversos momentos do cotidiano escolar e se relaciona às primeiras construções que temos sobre o campo de pesquisa. Expomos, a seguir, uma pequena parte da etnografia das experiências da primeira infância, registrados em caderno de campo.

No momento de entrada dos bebês, que ocorre às $7 \mathrm{~h}$ da manhã, chegou um menino negro chamado Daniel. As funcionárias ${ }^{2}$ se olharam e comentaram: "Poxa, o Daniel sumiu e voltou. Caramba, ele bate e morde as outras crianças, e pior que ele faz de propósito, parece que gosta de bater nos mais frágeis." O menino teve a roupa trocada, como é de praxe durante a entrada, e começou a chorar pedindo o colo da mãe. Logo em seguida, a auxiliar Karina o colocou no berço, demonstrando um comportamento de afastamento em relação ao choro da criança. O menino não tinha muita frequência no berçário e havia entre as auxiliares o comentário de que ele batia nas outras crianças. Por essa razão, elas sempre o colocavam no berço, como uma tentativa de preservar a tranquilidade no salão do berçário. Também eram tecidos alguns comentários acerca da beleza

\footnotetext{
$2 \quad$ Os nomes fictícios das auxiliares de creche são citados no corpo deste artigo, porém o intuito desse trabalho é dialogar com a relação entre os docentes e os bebês, visto que parte da função docente a elaboração de estratégias para se estruturar o direcionamento pedagógico.
} 
desse menino, mas os principais se relacionavam ao seu comportamento ruim. $\mathrm{O}$ seu destino era traçado nas falas de que ele aprontaria ainda mais quando ficasse com mais idade.

O salão onde ficam todas as crianças possui momentos para a realização de todas as atividades de cuidado e educação. Porém, o brincar está sempre presente, os livros são acessíveis a todas as crianças, assim como caixas, brinquedos, ursos, bonecas e bolas. No momento de "contação de história", a professora senta-se em um canto da sala e chama os bebês, atraindo-os com livros. Ela cria uma pequena roda com os que desejam ouvir as historinhas e eles se mostram muito entusiasmados, pois entregam em suas mãos livrinhos e apontam os personagens. Nessa ocasião, a regente pegou um livro de pano sobre Branca de Neve, feito com ilustrações que tinham a figura masculina e a feminina. Ela o mostrou para um menino chamado Paulo, que olhava fixamente os desenhos. Em seguida, disse: "Olha o papai, olha a mamãe." E comentou: "Não adianta você não vai se reconhecer mesmo, só tem brancos na história." Segundo os apontamentos de Fanon (2008, p. 128), "uma criança negra normal, tendo crescido no seio de uma família normal, ficará anormal ao menor contato com o mundo branco." Esse pensamento ilustra como a infância da criança negra já carrega os padrões do mundo do branco europeu, os quais a inserem no complexo de inferioridade que rege o negro dentro da sociedade.

A docente demonstrou preocupar-se com a ausência de livros na creche que representassem as crianças negras. Desse modo, é visível que o corpo negro não é representado na primeira infância no espaço da creche, pois as primeiras referências de família e de beleza remetem a personagens brancos dos contos de fada.

Partindo desse princípio, sabemos que a educação, como uma técnica, é responsável pela educação dos corpos e pela construção identitária do sujeito. O comportamento dos adultos influencia, portanto, a educação corporal dos pequenos. Um dos fatos relacionados a isso tem a ver com a percepção dos bebês em relação ao tratamento dado a outros bebês. Uma menina, Rita, percebia quando sua colega (loira, branca e com olhos verdes) era recebida com sorrisos e tomada ao colo logo que expressava choro ou insatisfação. Quando chegava o momento da entrada, a menina punha-se a chorar e a olhar para as auxiliares e, por vezes, para mim. O seu comportamento retratava o desejo de colo e de atenção. Rita é negra, tem cabelos bem curtos e, segundo a professora, já foi confundida com um menino por alguns pais de outras crianças. A educadora a achava muito esperta e dizia que ela era uma das crianças mais inteligentes, apesar de não ser uma das mais paparicadas.

A rotina era demarcada por ações reproduzidas sem reflexão por parte das auxiliares e da professora, pois elas cuidavam de todas as crianças de maneira igualitária, embora as crianças consideradas "fofas" e "bonitas" fossem recebidas com mais sorrisos e simpatia, o que colaborava para o sentimento de segurança dos pequenos que sempre procuravam afago no colo das profissionais. A educação infantil é muito importante para a formação de conceitos, conhecimentos do mundo, pois significa para os bebês a experienciação do mundo, das imagens. A professora, em conjunto com suas auxiliares, costumava apresentar bonecas para os pequenos, e prevalecia entre eles o interesse por bonecas negras. Os bonecos negros eram manuseados, assim como uma boneca indígena que fazia parte das brincadeiras travadas na sala. Dessa maneira, integrar a criança aos brinquedos que 
representem a diversidade brasileira é de suma importância para a reeducação das relações étnicoraciais em sala.

Em suas ações pensadas, a docente busca não realizar divisões. Contudo, essa divisão já existe, pois os carinhos e beijos são destinados às crianças vistas como bonitas esteticamente. A beleza à qual nos referimos não se expressa na cor da pele, mas sim nos traços vistos como harmoniosos. Nesse sentido, a ação da auxiliar Kátia em relação a uma menina muito quieta, na opinião dela, chamou minha atenção. Ela pegou Samira, uma criança branca de cabelos loiros, e disse: "Poxa, Samira, eu quase não te pego no colo, você é sempre tão calada, fica na sua." A profissional relatou que quase não manifestava estímulos à menina que pouco interagia. Do mesmo modo, Nilza, uma menina de tom de pele bem escuro, também não interage muito com os outros bebês e nem com os adultos e essa pouca interação não foi reconhecida e pensada pelas profissionais, o que nos direcionou a pensar o motivo pelo qual umas crianças são mais percebidas do que outras.

Nesse mesmo dia, uma criança empurrou a outra e a auxiliar disse: "Poxa, não empurra ela não. Olha, é uma menina branca, bonita pra você brincar." Dessa maneira, criam-se muitas interrogações, pois qual é o lugar da beleza? O branco é que é bonito? Ensina-se muito cedo o que é bonito e, nesses ensinamentos que se relacionam à estética, o ideal de beleza forja-se no fenótipo do branco. O corpo branco é exaltado como sinônimo de beleza e é educado para ser sentido como tal, enquanto o corpo negro é submetido ao que Fanon (2008) chama de aparição social envoltada na cor, pois todas as ações do branco são pautadas nesse aspecto.

Nesse processo de enraizamento, percebemos que as condutas dos educadores e pais são parte integrante na construção de posturas e olhares dos pequenos. A forma pela qual os corpos são tocados e tratados é inserida no sujeito, formando assim os hábitos, o costume. A criança é habituada a agir, a se relacionar de uma determinada forma. A educação recebida condiciona negros e brancos a seguir o direcionamento social.

As agentes, assim como a professora, dão muita atenção a questões relacionadas à estética e à higiene apresentada pelos pequenos. No momento do café da manhã, a professora olhou para o cabelo da menina Rita e comentou com a auxiliar: "Nossa, olha o cabelo dessa criança!" As profissionais reclamavam muito da ausência de higiene da menina no âmbito familiar. A auxiliar Karina sempre fazia penteados na menina e reclamava do fato de ela passar o final de semana com o mesmo penteado. Essa mesma auxiliar, certo dia, relatou que um familiar ia adotar uma menina negra e que a primeira coisa que sua esposa iria fazer seria: "dar um jeito nos cabelos da criança, porque, em sua opinião, tinha o cabelo ruim". A mesma mulher era branca e possuía cabelos crespos, relaxados por química. Dessa maneira, destaco o quanto está assimilada em nossa sociedade a ideia de que o negro possui o cabelo ruim e que esse cabelo precisa ser domado, alisado, para ser bonito e aceito. Essa assimilação é realizada pela criança no decorrer de sua passagem pela escola e pelas referências que a cercam dentro da sociedade. Segundo Malachias (2007, p. 39): "a negação de outros padrões de beleza transformou o cabelo liso em referência máximo de beleza - e isto não é aceitável porque não corresponde a realidade, pois a diversidade étnica propicia diferentes estilos de beleza." 
A relação entre adultos e bebês nesse espaço parte primeiramente das ações de cuidar/ educar. Nelas foram constatados apontamentos em relação à corporeidade das crianças, pois os adultos costumam chamar os pequenos por alguns apelidos relativos às suas características físicas e comportamentais. A forma como uma criança se comporta rende classificações, como: a "mais bagunceira", a que "come demais" ou a "briguenta" que empurra os colegas tentando pegar o brinquedo. Há um apelo à ordem, aos bons modos e, principalmente, à boa higiene e aos cuidados com os cabelos, no caso das meninas. As crianças recebiam apelidos correspondentes à sua forma física ou ao seu comportamento no berçário. Os apelidos como "Bagulhão" eram destinados à Dora, uma menina negra com sobrepeso, que sempre puxava os brinquedos dos seus colegas, segundo relatou a professora. Outras crianças com sobrepeso, como Áurea, uma menina branca, também eram apelidadas. A docente e suas auxiliares a chamavam de "Buchanchuda", devido ao seu andar e à sua aparência. Havia um menino negro chamado Ângelo que era apelidado pela docente de "Negão Cheiroso". Certo dia, a professora perguntou à mãe da criança se podia chamá-lo assim, e a mãe permitiu, dizendo que o chamavam assim na rua.

A linguagem indica a colonização das mentes imbuídas pela violência racista a que foram submetidas. Nesse âmbito, construir uma autoimagem positiva através das ações pedagógicas pensadas pelos adultos é vital para a criança negra. A docente relatou, por vezes, a preferência de uma aluna por uma boneca de pano negra e notou que a criança não se separava do brinquedo.

A história do negro brasileiro com os seus cabelos circula na creche em uma diversidade de momentos e apresenta-se, em conversas paralelas, como na fala da auxiliar Karina, ao mencionar uma criança da turma: "Poxa, a Júlia é branca e bonita, tem olhos azuis. Ela devia fazer comercial de TV. Eu só não levo a minha filha porque não tenho tempo. Vocês sabem que na TV eles gostam de criança branca e comunicativa, né? Vocês sabem que tem racismo." Essa fala destaca como o racismo é forte e prevalece na mídia e nos demais espaços sociais. A beleza é associada ao branco e a feiura ao negro, que sempre recebe os papéis vinculados à subalternidade. Essa divisão é aprendida precocemente e avança a partir da convivência com o outro e com outros midiáticos. A estética corporal do negro, portanto, é culturalmente rejeitada e relacionada à negatividade.

Em certa ocasião, a professora comentou sobre a mãe de determinada aluna negra, dizendo confundi-la com a de outra aluna detentora de uma pele mais clara. A docente comentou com a auxiliar Karina: "Nossa, eu confundi a mãe dela com a mãe da Nilza... Achei que a mãe dela fosse a mãe da Nilza, aquela branquinha [a mãe era parda], a mãe dela é escurinha." É muito comum o uso dos termos: "escuro" e "escurinho" para se referir à cor do negro. A cor escura é associada ao mal, ao que é ruim. Essa maneira de classificar a cor e, portanto, o pertencimento racial, provoca no negro um sentimento de inferioridade, acarretando o desejo de fugir da cor. A ascendência negra é vista como algo que precisa ser superado ou ressignificado pelas técnicas de branqueamento.

A questão chama atenção pelo fato de como a autorrejeição da aparência é destinada aos negros de forma impiedosa. Em determinado dia, a aluna Eliane, negra e detentora de cabelos crespos, chegou à creche muito feliz e entusiasmada para brincar. "A regente relatou que há muito tempo não via a menina tão feliz: desde que ela cortou o cabelo por causa de uma doença ficou 
triste, ela era brincalhona, agora está masculinizada." Pude identificar que os cabelos compridos são vistos pela professora como sinônimo do que é feminino.

Desde muito jovens as mulheres negras são socializadas para terem o cabelo alisado, muitas relataram experiências em que a família e, principalmente, a mãe, impunha que elas tivessem os cabelos alisados. Na fase adulta, algumas alisam o cabelo porque de fato acham que o cabelo alisado fica mais bonito, enquanto outras alegam questões relativas ao cotidiano do uso do cabelo crespo e, em parte, justificam a intervenção no cabelo como uma forma de torná-lo mais prático no cotidiano. (FIGUEIREDO, 2002, p. 5).

A sua visão social exemplificou o que é difundido nos espaços midiáticos e também pelo imaginário social, de que a mulher para ser feminina não pode ter cabelos curtos. Assim, a valorização da beleza feminina passa pelos seus cabelos, que aparecem nesse contexto como referência, inaugurando o estar no mundo para o negro. Na creche, o menino Amadeu é sempre visto como inteligente e esperto, porém sua estética é pouco elogiada. Além disso, os gracejos lançados às crianças de cabelos lisos não são repartidos com o bebê negro da mesma maneira. E é por meio das interações, dos abraços, sorrisos e ações corporais que a criança vai se apropriando do mundo e das práticas sociais. Desse modo, o cotidiano possibilita entender a engenhosidade das relações raciais estruturadas pelo racismo. Segundo Silva Jr. (2012), a política educacional deve estar informada e habilitada para identificar valores negativos aprendidos socialmente (nomeadamente preconceitos e estereótipos) e impedir que tais valores comprometam a qualidade da educação e violem direitos das crianças.

A creche é comumente um espaço onde os discursos sobre a aparência preponderam. Assim, as crianças fora do padrão de peso são denominadas de "fofas" e as que possuem determinadas características físicas têm sua aparência comentada. Rita possui cabelos crespos e curtos e, devido a isso, as auxiliares e a professora sempre comentam sobre como a criança é cuidada de forma "largada". Elas demarcam a todo o momento a importância da boa higiene e dos padrões de beleza que mostram a feminilidade, como roupinhas mais infantis e penteados. É interessante notar como as ações emergidas das questões que tangem a chamada "boa aparência" são recolocadas o tempo todo dentro do comportamento das profissionais. As desigualdades entre brancos e negros marcam praticamente todos os campos da vida social no Brasil. No sistema de ensino não é diferente, no que diz respeito à educação infantil este nível de ensino não contempla as demandas da população em idade escolar.

O processo de exclusão atinge grupos em situação de vulnerabilidade social, como negros e indígenas. O Brasil contemporâneo vive o seguinte dilema: de um lado contamos como uma legislação avançada que reconhece os direitos a todas as crianças; de outro, um panorama de intensas desigualdades entre brancos e negros no sistema de ensino. Cabe observar que nesta década já conseguimos democratizar o acesso ao ensino fundamental, no entanto o acesso à creche ainda é insuficiente, carecendo de políticas e de práticas educativas que garantam a cidadania de todos os segmentos sociais, em especial negros e indígenas.

A educação infantil pode ser entendida como a porta principal para ingresso e sucesso no sistema de ensino. De acordo com Bento (2012), o reconhecimento da educação infantil, particularmente o da creche, como instituição pública no âmbito da educação foi sancionado pela Constituição Federal de 
1988. A denominada "constituição cidadã" conferiu direitos a segmentos sociais como: as mulheres, os/as negros/as, os/as indígenas, os/as portadores/as de necessidades especiais, idosos, as crianças e os/as adolescentes, grupos, até negligenciados, passaram a receber atenção especial. Segundo Henriques (2002), independente da raça, os estudantes cuja formação possui o nível pré-escolar desfrutam de melhores oportunidades educacionais que lhe são concedidas. Nesse sentido, racismo age como fator determinante que, ao construir barreiras que impedem o acesso, a permanência e a transmissão de conteúdos adequados à construção da cidadania dos afro-brasileiros, os impedem de usufruir plenamente do processo de iniciação à vida escolar.

\section{CONSIDERAÇÕES FINAIS}

A pesquisa objetivou entender como são tratados os corpos das crianças negras na educação infantil, tendo como principal foco compreender de que maneira o cabelo crespo, enquanto marcador de identidade étnico-racial, é visto, tratado e pensado pelos envolvidos nas relações estabelecidas no interior da creche, considerando que o cabelo é um importante compositor do fenótipo negro. Desse modo, as entrevistas e observações foram utilizadas para pensar as relações raciais na creche por meio do primeiro contato da criança negra com o ambiente educacional.

O estudo apontou para a importância do trabalho docente dentro de uma perspectiva que abrange a quebra do silêncio em torno do racismo e das formas correlatas de estigmatização do outro e no cumprimento legal dos direitos da criança, tanto negra como branca, de construir uma identidade positiva ao conviver com a diversidade étnico-racial presente em sala de aula e nos demais espaços sociais.

Dessa maneira, quando falamos a respeito do cabelo crespo nos deparamos com uma realidade fortemente demarcada pelo racismo. O processo histórico de lutas proporcionou o direito a um ensino que contemple a diversidade étnico-racial, com a lei no 10.639/03. Sabemos que a realidade nacional traz para as creches e pré-escolas uma diversidade étnico-racial na qual prevalece uma gama de estereótipos, culturas e religiões que constituem a identidade de bebês e de crianças pequenas e que não podem ser negligenciados pela escola. A lei ainda não alcança a educação infantil e, desse modo, destacamos a importância de a lei atingir a primeira infância para que as instituições teçam uma pedagogia voltada para as práticas antirracistas.

Nas entrevistas e na observação das práticas docentes pudemos constatar que, apesar da formação pedagógica das duas docentes dessa creche municipal, ambas demonstraram que o racismo é um elemento estruturante em nossa sociedade, e é possível identificá-lo nos seus discursos, pelos apelidos pejorativos atribuídos às crianças negras. Daí a necessidade de uma formação centrada nos pressupostos de combate ao racismo por meio de uma educação voltada para as relações étnico-raciais. Os auxiliares de creche no momento da pesquisa ainda não tinham formação para o magistério. As suas falas e ações cotidianas eram pautadas nas ideias de senso comum. Desse modo, é possível identificar em suas posturas o olhar difundido socialmente a respeito do cabelo crespo e das demais características fenotípicas das crianças negras. 
Quanto aos pais e responsáveis, notamos que o racismo no Brasil é velado e sutil; herdamos a ideia de que vivemos em uma democracia racial e que, portanto, negros, brancos e indígenas convivem em harmonia. As marcas dessa difusão ainda vigoram em nossa sociedade e podem ser observadas em grande parte das falas. As mães e avós, assim como grande parte da população brasileira, consideram a existência do preconceito, mas, no entanto, não se consideram racistas.

Desse modo, ressaltamos a importância de formação profissional para que os docentes identifiquem as práticas racistas e seus mecanismos. Cremos que a formação para se trabalhar com a questão racial é uma importante forma de se reverter o quadro preconceituoso que atravessa a experiência de socialização da criança pequena. Precisamos reconhecer que a abolição da escravidão ainda é um processo inacabado, pois é possível combater a desigualdade sem falar em racismo. Para além da necessidade da democratização do acesso à educação infantil há que se oferecer uma educação de qualidade com práticas e conteúdos que valorizem o potencial de todas as crianças independente da cor ou outra qualquer distinção. O combate ao racismo institucional por meio de interações positivas entre adultos e as crianças são indispensáveis para o pleno desenvolvimento e para a construção de uma educação antirracista. 


\section{REFERÊNCIAS BIBLIOGRÁFICAS}

BENTO, M. A. S. Apresentação. In: (org.). Educação infantil, igualdade racial e diversidade: aspectos políticos, jurídicos, conceituais. São Paulo: CEERT, 2012.

CAVALLEIRO, Eliane. Do silêncio do lar ao silêncio escolar: racismo, preconceito e discriminação na educação infantil. São Paulo: Summus, 2000.

FANON, Frantz. Os condenados da terra. Rio de Janeiro: Civilização Brasileira, 1968.

. Pele negra, máscaras brancas. Salvador: EDUFBA, 2008.

FIGUEIREDO, Angela. Cabelo, cabeleira, cabeluda, descabelada: identidade, consumo e manipulação de aparência entre os negros brasileiros. In: REUNIÃO ANUAL DA ASSOCIAÇÃO NACIONAL DE PÓS- GRADUAÇÃO: Pesquisa em Ciências Sociais. 26. 2002. Caxambu. Anais... Caxambu, 2002.

GELEDÉS. Entenda o que é racismo institucional. Disponível em: <https://racismoinstitucional. geledes.org.br/o-que-e-racismo-institucional/>. Acesso em: 20/12/2018.

GUIMARÃES, Daniela. Relações entre bebês e adultos na creche: o cuidado como ética. São Paulo: Cortez, 2011.

HENRIQUES, Ricardo. Raça e gênero no sistema de ensino: os limites das políticas universalistas na educação. Brasília: Unesco, 2002.

HOOKS, Bell. Alisando o nosso cabelo. Revista Gazeta de Cuba, Unión de Escritores y Artistas de Cuba, jan./fev. 2005. Disponível em: <http://coletivomarias.blogspot.com.br/2008/05/ alisando-o-nosso-cabelo.html>. Acesso em: 3/08/2014.

JACCOUD, L. O combate ao racismo e à desigualdade: o desafio das políticas públicas de promoção da igualdade racial. In: THEODORO, M. (org.). As políticas públicas e a desigualdade racial no Brasil 120 anos após a abolição. Brasília: IPEA, 2008.

MALACHIAS, Rosangela. Cabelo bom, cabelo ruim. São Paulo: NEINB, 2007.

MAUSS, Marcel. Sociologia e antropologia. São Paulo: Cosac Naify, 2003.

. Mauss e a educação. Belo Horizonte: Autêntica, 2011.

MIRANDA, Maria Aparecida; MARTINS, Marilza de Souza. Maternagem: quando o bebê pede colo. São Paulo: NEINB, 2007.

OLIVEIRA, Fabiana de; ABRAMOWICZ, Anete. Infância, raça e "paparicação". Educação em Revista, Belo Horizonte, v. 26, n. 2, p. 209-226, 2010.

ROSEMBERG, Fúlvia. A criança pequena e o direito à creche no contexto do debate sobre infância e relações raciais. In: BENTO, Maria Aparecida Silva (org.). Educação infantil, igualdade racial e diversidade: aspectos políticos, jurídicos, conceituais. São Paulo: CEERT, 2012. p. 11-46.

SILVA JUNIOR, H. Discriminação racial nas escolas: entre as leis e as práticas sociais. Brasília: Unesco, 2002. 
. Anotações conceituais e jurídicas sobre educação infantil, diversidade e igualdade racial. São Paulo: CEERT, 2012. Disponível em: <http://portal.mec.gov.br/index. php?option=com_docman\&view=download\&alias=11283-educa-infantisconceituais\&ltemid=30192>. Acesso em: 20/12/2018.

WIEVIORKA, Michel. O racismo: uma introdução. São Paulo: Perspectiva, 2007. 